\title{
¿ES POSIBLE ESTABLECER LA OBLIGATORIEDAD DE LA VACUNACIÓN CONTRA EL SARS-COV-2 EN EL ÁMBITO LABORAL?
}

\author{
Raquel Poquet Catalá \\ Profesora asociada de la Universidad de Valencia
}

\begin{abstract}
En este trabajo se analiza una cuestión muy candente en el ámbito laboral en los momentos actuales, cuál es la posibilidad de obligar a las personas trabajadoras a someterse a la vacunación contra el SARS-COV-2. Para ello, se realiza un primer análisis de la normativa general en materia de sanidad y vacunación, así como las posibilidades de ser implementada de forma obligatoria en situaciones de declaración de estado de alarma, sitio o excepción. Posteriormente, se analiza la normativa laboral, especialmente, en materia de seguridad y salud en el trabajo.

In this work it is analyzed a very burning issue in the workplace at the present time, which is the possibility of forcing workers to undergo vaccination against SARS-COV-2. For this, it its carried out a first analysis of the general regulations on health and vaccination, as well as the possibilities of being implemented on a mandatory basis in situations of declaration of a state of alarm, site or exception. Subsequently, it is analyzed the labor regulations, especially in matters of safety and health at work.
\end{abstract}

Title: Is it possible to establish the compulsory of vaccination against SARS-COV-2 in the workplace?

Palabras clave: vacuna, COVID-19, obligatoriedad, salud, integridad física. Key words: vaccination, COVID-19, obligatory, health, physical integrity.

IUSLabor 1/2021, ISSN 1699-2938, p. 6-27

DOI. 10.31009/IUSLabor.2021.i02.01

Fecha envío: 18.4.2021 | Fecha aceptación: 23.4.2021 


\section{Sumario}

1. Introducción

2. ¿Es la vacunación obligatoria en España a nivel general?

2.1. Contexto normativo

2.2. Posición de la doctrina judicial

3. Consentimiento informado

4. ¿Es posible establecer la obligatoriedad de la vacunación en el ámbito laboral?

4.1. Contexto normativo laboral general

4.2. Contexto normativo del personal sanitario

4.3. Despido de una persona trabajadora por negarse a ser vacunada, ¿es posible?

5. Reflexiones finales

6. Bibliografía 


\section{Introducción}

La actual crisis sanitaria mundial, y también económica, social y cultural, en la que estamos sumergidos ha cambiado los principios y objetivos de la sociedad. En estos momentos, no cabe duda de que uno de los hitos más aplaudidos es la consecución de una vacuna que pueda dar luz a las esperanzas sobre el final de la pandemia.

No obstante, la implantación de la vacunación plantea una importante controversia sobre sus riesgos y su efectividad, debate que en el ámbito jurídico no queda exenta de polémica, especialmente, sobre su posible obligatoriedad, sea de forma generalizada o en ámbitos concretos, como el laboral.

De cualquier forma, debe advertirse que este debate sobre las vacunas no es nuevo de ahora, pues, aunque en menor afectación y medida, ya se planteó en su configuración como requisito para acceder a determinados servicios o actividades, como guarderías o colegios.

En general, puede señalarse que existen diferentes modelos en materia de vacunación. Por un lado, aquel modelo que considera que determinadas vacunas son obligatorias, mientras que otras son recomendadas, como el caso de Italia o Francia. En segundo lugar, aquel que aboga por la plena autonomía del paciente, de tal forma, que será este quien decida si se vacuna o no de forma libre y voluntaria. En tercer lugar, aquel que se basa en una política de incentivos fiscales para aquellos que opten por la vacunación, como el caso de Australia. Y, por último, aquel que se vertebra en la imposición de sanciones pecuniarias o la imposibilidad de acceder a determinados servicios públicos si no se está vacunado.

No obstante, la comunidad científica ${ }^{1}$ considera que una medida de vacunación obligatoria podría tener efectos contrarios al deseado, por lo que debe abogarse por campañas de sensibilización y de concienciación. "La ausencia de una norma que permita promover una medida pública de vacunación obligatoria fuera del supuesto concreto de epidemia, se muestra, prima facie, como un déficit de nuestro sistema jurídico, sobre todo, atendidas las recientes experiencias de los países de nuestro entorno y algunos casos acaecidos recientemente en nuestro propio país. Por lo tanto, parece adecuado que, junto al impulso de medidas de educación, información y promoción de conductas favorables por parte de la población a la vacunación como política principal de salud pública, puedan imponerse, en supuestos concretos, la vacunación obligatoria,

\footnotetext{
${ }^{1}$ Comité de Bioética de España, Cuestiones ético-legales de rechazo a las vacunas y propuestas para un debate necesario. Disponible en http://assets.comitedebioetica.es/files/documentacion/cuestiones-eticolegales-rechazo-vacunas-propuestas-debate-necesario.pdf
} 
por ejemplo, cuando las tasas de vacunación se aprecie que se ven reducidas de manera que se pierda el efecto rebaño, sin necesidad de esperar a que aparezca una epidemia o, incluso, un mero brote".

\section{2. ¿Es la vacunación obligatoria en España a nivel general?}

\subsection{Contexto normativo}

Antes de analizar el ordenamiento jurídico español, debe hacerse referencia a los textos normativos internacionales. Por un lado, la Carta de los Derechos Fundamentales de la $\mathrm{UE}^{2}$-reconocida con el mismo valor jurídico que los Tratados por el artículo 6.1 TUE-, señala en su artículo 3 que toda persona tiene derecho a la integridad física y psíquica, obligando a respetar, en el marco de la medicina y la biología "el consentimiento libre e informado de la persona de que se trate, de acuerdo con las modalidades establecidas por la ley". Asimismo, el Convenio para la protección de los derechos humanos y la dignidad del ser humano con respecto a las aplicaciones de la biología y la medicina ${ }^{3}$ recoge en su artículo 5 que sólo podrá realizarse una intervención en el ámbito de la sanidad si la persona afectada da "su libre e informado consentimiento", para lo cual "deberá recibir previamente una información adecuada acerca de la finalidad y la naturaleza de la intervención, así como sobre sus riesgos y consecuencias". No obstante, su artículo 8 señala que cuando por motivos de urgencia no pueda obtenerse el consentimiento adecuado, será posible proceder inmediatamente "a cualquier intervención indispensable desde el punto de vista médico a favor de la salud de la persona afectada".

Por otro lado, el Convenio Europeo de Derechos Humanos ${ }^{4}$ no contiene una norma específica sobre el derecho a la integridad física y moral, pero el TEDH ha señalado que el respeto a la "vida privada", consagrado en el artículo 8.1 CEDH engloba el derecho a la integridad física y moral ${ }^{5}$, así como también el derecho a la participación de las personas en la elección de los actos médicos de los que sean objeto, así como las relativas a su consentimiento ${ }^{6}$. Ello significa que la imposición de un tratamiento médico sin dicho consentimiento, si el paciente no está incapacitado, supone un ataque a la integridad física del afectado.

\footnotetext{
${ }^{2}$ De 7 de diciembre de 2000.

${ }^{3}$ De 4 de abril de 1997.

${ }^{4}$ De 4 de noviembre de 1950.

${ }^{5}$ SSTEDH de 16 de diciembre de 1997, caso Raninen C. Finlandcia; de 24 de febrero de 1998, caso Botta c. Italia.

${ }^{6}$ SSTEDH de 24 de septiembre de 1992, caso Herczegfalvy c. Austria; de 29 de abril de 2002, caso Pretty c. Reino Unido.
} 
En España, debe partirse de que la vacunación es voluntaria, pues nuestro ordenamiento jurídico no contiene ningún deber expreso de vacunación, y nadie puede ser, en principio, obligado a vacunarse.

De hecho, si se analizan los antecedentes normativos, tampoco se halla ninguna regulación normativa que establezca su obligatoriedad. Por un lado, la Ley de Bases de la Sanidad Nacional de 25 de noviembre de 1944, la cual fue modificada por la Ley 22/1980, de 24 de abril, señalaba en su base IV que "las vacunaciones contra la viruela y la difteria y contra las infecciones tíficas y paratíficas, podrán ser declaradas obligatorias por el Gobierno cuando, por la existencia de casos repetidos de estas enfermedades o por el estado epidémico del momento o previsible, se juzgue conveniente. En todas las demás infecciones en que existan medios de vacunación de reconocida eficacia total o parcial y en que esta no constituya peligro alguno, podrán ser recomendados y, en su caso, impuestos por las autoridades sanitarias". Asimismo, la Ley 3/1986 de Medidas Especiales en Materia de Salud Pública de 14 de abril, recogía en su artículo 2 que "las autoridades sanitarias competentes podrán adoptar medidas de reconocimiento, tratamiento, hospitalización o control cuando se aprecien indicios racionales que permitan suponer la existencia de peligro para la salud de la población debido a la situación sanitaria concreta de una persona o grupo de personas o por las condiciones sanitarias en que se desarrolle una actividad". Su artículo 3 recogía que "con el fin de controlar las enfermedades transmisibles, la autoridad sanitaria, además de realizar las acciones preventivas generales, podrá adoptar las medidas oportunas para el control de los enfermos, de las personas que estén o hayan estado en contacto con los mismos y del medio ambiente inmediato, así como las que se consideren necesarias en caso de riesgo de carácter transmisible". Por tanto, según un sector doctrinal, de estos preceptos podría extraerse una habilitación legislativa para establecer la vacunación obligatoria en caso de pandemia, facultando al Estado ya las Comunidades Autónomas para establecer medidas limitativas de derechos fundamentales, como así se ha hecho en el último año con derechos relacionados con la libre circulación de las personas. No obstante, a mi parecer, estimo que, aunque, a primera vista pudiera parecer que de ahí se podría derivar la vacunación con carácter obligatorio, no es así, pues el derecho a la autonomía del paciente se halla por encima de cualquier otro derecho.

Por otro lado, debe indicarse que la LO 4/1981, de 1 de junio, de estados de alarma, excepción y sitio, establece en su artículo 4 que, para estas situaciones, "el Gobierno, en uso de las facultades que le otorga el artículo 116.2 de la Constitución, podrá declarar el estado de alarma, en todo o parte del territorio nacional, cuando se produzca alguna de las siguientes alteraciones graves de la normalidad: b) crisis sanitarias, tales como las epidemias". Y en su artículo 12 autoriza a que, en dichos casos, "la autoridad competente podrá adoptar por sí, según los casos, además de las medidas previstas en 
los artículos anteriores, las establecidas en las normas para la lucha contra las enfermedades infecciosas".

A este respecto, el TC ha declarado que el Real Decreto que declara el estado de alarma tiene rango de ley, en la medida en que activa una competencia extraordinaria del Estado que de por sí afecta a la eficacia de las competencias atribuidas por los Estatutos de Autonomía y las demás leyes ${ }^{7}$. De hecho, se ha podido comprobar como el recurso a la declaración del estado de alarma, que, hasta hace alrededor de un año, era una situación rarísima, sin embargo, ahora se ha convertido en un escenario "normal".

La LO 14/1986, de 25 de abril, General de Sanidad, establece en su artículo 1 que "en caso de que exista o se sospeche razonablemente la existencia de un riesgo inminente y extraordinario para la salud, las autoridades sanitarias adoptarán las medidas preventivas que estimen pertinentes, tales como la incautación o inmovilización de productos, suspensión del ejercicio de actividades, cierres de empresas o de sus instalaciones, intervención de medios materiales y personales y cuantas otras consideren sanitariamente justificadas".

De cualquier forma, con carácter general, las vacunas, como materia propia de salud pública, son apenas mencionadas en la Ley 33/2011, de 4 de octubre, General de Salud Pública, en cuyo artículo 5.2 se parte de la regla general de voluntariedad, señalándose que "sin perjuicio del deber de colaboración, la participación en las actuaciones de salud pública será voluntaria, salvo lo previsto en la Ley Orgánica 3/1986, de 14 de abril, de medidas especiales en materia de salud pública".

Por su parte, la LO 3/1986, de 14 de abril, de medidas especiales en materia de salud pública, establece en su artículo 1 que "al objeto de proteger la salud pública y prevenir su pérdida o deterioro, las autoridades sanitarias de las distintas Administraciones Públicas podrán, dentro del ámbito de sus competencias, adoptar las medidas previstas en la presente Ley cuando así lo exijan razones sanitarias de urgencia o necesidad". Por su parte, el artículo 2 señala que "las autoridades sanitarias competentes podrán adoptar medidas de reconocimiento, tratamiento, hospitalización o control cuando se aprecien indicios racionales que permitan suponer la existencia de peligro para la salud de la población debido a la situación sanitaria concreta de una persona o grupo de personas o por las condiciones sanitarias en que se desarrolle una actividad", y su artículo 3 dispone que "con el fin de controlar las enfermedades transmisibles, la autoridad sanitaria, además de realizar las acciones preventivas generales, podrá adoptar las medidas oportunas para el control de los enfermos, de las personas que estén o hayan

${ }^{7}$ STC 83/2016, de 28 de abril. 
estado en contacto con los mismos y del medio ambiente inmediato, así como las que se consideren necesarias en caso de riesgo de carácter transmisible".

De estos preceptos se puede deducir que, en casos de epidemias, se podría imponer legalmente la vacunación con carácter obligatorio cuando exista un riesgo colectivo para la salud pública, desplazando en dichos supuestos el principio general de voluntariedad en la vacunación ${ }^{8}$. Pero fuera de este supuesto no se puede establecer la vacunación como obligatoria.

Cabe destacar que la LO 3/1986 fue elaborada y publicada en el BOE junto con la LO 14/1986, de la que formaba parte originariamente, pues el legislador fue consciente de que las competencias de urgencia que atribuía a las autoridades sanitarias podrían restringir derechos fundamentales. Es decir, "la citada Ley Orgánica permite a la autoridad sanitaria, es decir, al Estado y a las Comunidades Autonómicas, en situaciones epidémicas graves, adoptar todas las medidas necesarias para garantizar la salud pública. Si se adoptó con el rango de Ley Orgánica fue precisamente para despejar cualquier duda que pudiera existir sobre la posibilidad de que la autoridad sanitaria adoptara las medidas necesarias restrictivas de derechos cuando así lo requiriera la protección de la salud pública"9.

Además, por otro lado, la Ley 41/2002, de 14 de noviembre, básica reguladora de la autonomía del paciente y de derechos y obligaciones en materia de información y documentación clínica, establece en su artículo 9.2 a) que "los facultativos podrán llevar a cabo las intervenciones clínicas indispensables en favor de la salud del paciente, sin necesidad de contar con su consentimiento, en los siguientes casos: a) Cuando existe riesgo para la salud pública a causa de razones sanitarias establecidas por la Ley. En todo caso, una vez adoptadas las medidas pertinentes, de conformidad con lo establecido en la Ley Orgánica 3/1986, se comunicarán a la autoridad judicial en el plazo máximo de 24 horas siempre que dispongan el internamiento obligatorio de personas". Esta previsión normativa prevé que el principio general de autonomía de la voluntad cede en determinadas situaciones, en las que es posible realizar intervenciones de salud sin consentimiento de los interesados, como cuando existe riesgo para la salud pública.

Por tanto, y como conclusión, se puede indicar que la regla general en nuestro Derecho es la no obligatoriedad de la vacunación siendo necesario, además, el consentimiento del interesado o sus representantes legales. Sólo excepcionalmente, la LO 3/1986 permite

\footnotetext{
${ }^{8}$ Así lo considera también TOLOSA TRIBIÑo, César, "Problemas legales de la vacunación en España", Diario La Ley, 22 de enero de 2021.

${ }^{9}$ TOLOSA TRIBIÑo, César, "Problemas legales de la... op. cit.
} 
plantear la vacunación con carácter obligatorio en casos de epidemias y crisis sanitaria y riesgo efectivo para la salud pública.

Incluso, según el artículo 33 Ley 33/2011, parece que abre la puerta a que las Mutuas de Accidentes de Trabajo y Enfermedades Profesionales puedan colaborar en el proceso de vacunación, ya que el mismo prevé la posibilidad de "establecer mecanismos de coordinación en caso de pandemias u otras crisis sanitarias, en especial para el desarrollo de acciones preventivas y de vacunación" (artículo 33.2.h), pero sin que esta colaboración pueda suponer, en ningún caso, la obligatoriedad de la vacunación

Desde el punto de vista de la Constitución, su artículo 43 configura un derecho de dimensión individual, pero también colectivo, dirigido a la protección de los intereses generales, mediante el establecimiento de políticas dirigidas a la preservación de la salud de la población. Apoyándose en este precepto podría plantearse la posibilidad de implementar políticas de protección de la salud pública, como campañas de vacunación, como principio de actuación de los poderes públicos.

De cualquier forma, es el artículo $15 \mathrm{CE}$, precepto que recoge el derecho fundamental a la integridad física, el que constituye el eje sobre el que se sustenta y, al mismo tiempo, se desmorona toda esta encrucijada, pues, el derecho del paciente a aceptar o rechazar medidas terapéuticas forma parte del contenido esencial del derecho a la integridad física, que puede ser vulnerado por cualquier actuación que consiste en una intromisión no consentida en la esfera corporal del paciente. Por tanto, debe considerarse, y así lo estimo, que cualquier intervención médica realizada sin contar con la voluntad del paciente constituirá una vulneración de este derecho fundamental.

Nuestro máximo intérprete constitucional ${ }^{10}$ ha señalado que "evidentemente, las actuaciones médicas llevan implícita una posibilidad de afección a la integridad personal protegida por el artículo $15 \mathrm{CE}$, en la medida en que éste tutela la inviolabilidad de la persona contra toda intervención en su cuerpo, de manera que es preciso arbitrar los mecanismos necesarios para garantizar la efectividad del derecho dentro de ese ámbito, cohonestándolo con la función y finalidad propias de la actividad médica. Y es que, como señalamos en la STC 181/2000, de 29 de junio, FJ 8, la protección constitucional de la vida y de la integridad (física y moral) no se reduce al estricto reconocimiento de los derechos subjetivos necesarios para reaccionar jurídicamente frente a las agresiones a ellos inferidas, sino que, además, contiene un mandato de protección suficiente de aquellos bienes de la personalidad, dirigido al legislador y que debe presidir e informar toda su actuación. En lo que aquí interesa, esa garantía de la efectividad del derecho en

${ }^{10}$ STC 37/2011, de 28 de marzo. 
el ámbito implica que cualquier actuación que afecte a la integridad personal, para resultar acorde con dicho derecho, según la delimitación que antes efectuamos del mismo, se ha de encontrar consentida por el sujeto titular del derecho o debe encontrarse constitucionalmente justificada. De ahí que el legislador deba establecer (como en efecto ha hecho, según veremos posteriormente) los mecanismos adecuados para la prestación del consentimiento del sujeto que se ha de ver sometido a una intervención médica, así como los supuestos que, desde una perspectiva constitucional permitirían prescindir del mismo, teniendo siempre presente, de una parte "que no solo ante los límites que la propia Constitución expresamente imponga al definir cada derecho o ante los que de manera mediata o indirecta de la misma se infieran al resultar justificados por la necesidad de preservar otros derechos constitucionalmente protegidos, puedan ceder los derechos fundamentales".

De hecho, el TC acaba de admitir a trámite el recurso de inconstitucionalidad contra la Ley 8/2021, de 25 de febrero, de modificación de la Ley 8/2008, de 10 de julio, de Salud de Galicia, por la que, entre otros aspectos, porque el nuevo artículo 38.2.b.5. a de la Ley $8 / 2008$, según la redacción que le ha dado el apartado 5 del artículo único de la Ley 8/2021, prevé el "sometimiento a medidas profilácticas de prevención de la enfermedad, incluida la vacunación o inmunización”, en contra del Acuerdo sobre la Estrategia de Vacunación aprobado por el Consejo Interterritorial del Sistema Nacional de Salud el 28 de enero de 2021, con la oposición de cuatro comunidades autónomas (País Vasco, Cataluña, Galicia y Castilla y León), en el que se acordó que la misma "no es obligatoria”.

\subsection{Posición de la doctrina judicial}

En el ámbito de la doctrina judicial, debe citarse la STSJ Andalucía, de 22 de julio de $2013^{11}$, que confirma la vacunación forzosa de unos niños de Granada que no habían sido vacunados contra el sarampión, basándose en que el artículo 43.2 CE reconoce la facultad de las autoridades para inmunizar de forma forzosa a la población en casos excepcionales, en caso de que la gente no lo haga de forma voluntaria. Literalmente, la citada sentencia indica que "la convivencia en un Estado social y democrático de Derecho supone, no sólo el respeto de los derechos fundamentales a título individual, sino también que su ejercicio no menoscabe el derecho del resto de la sociedad que se rige por unas pautas de conducta que persiguen el interés general". Por ello, declara que en "el conflicto que se establece entre el derecho del Estado a imponer normas de obligado seguimiento para garantizar la salud de la ciudadanía y el derecho de los padres a decidir si sus hijos deben obtener esta protección, ha de darse preeminencia a los derechos protegidos por la

\footnotetext{
${ }^{11}$ St. núm. 2393/2013.
} 
administración sanitaria y que sustentan la adopción de la medida sanitaria acordada por el auto ahora apelado".

También puede citarse la STJS La Rioja, sala contencioso-administrativo, de 2 de abril de 2002, en relación a una resolución de la comunidad autónoma dejando sin efecto la concesión de una plaza en una guardería infantil a una menor al incumplir los requisitos de vacunación necesarios para su admisión, que señala que "nada impide tal opción alternativa y nada obliga a una vacunación que decididamente se rechaza. No puede desconocerse la potestad de la Administración para imponer tal exigencia a quien pretenda acogerse a los servicios de guardería, negando la admisión a los niños que no la cumplan, dado que la medida profiláctica aplicada resulta sanitariamente recomendable para la salud de todos los componentes del grupo (...) resultó conforme a Derecho denegar la admisión de éste a la guardería infantil si se incumplió el requisito del sometimiento a la vacunación oficial normativamente impuesta a tal fin". En términos similares también la STSJ Cataluña, sala contencioso-administrativo, de 28 de marzo de 2000, sobre una resolución de la Universidad Autónoma de Barcelona dejando sin efecto la matrícula de una menor en una Escola Bressol vinculada a la Universidad por la negativa de los padres a que se le inoculara cualquier tipo de vacuna, entendiendo la sala que la anulación de la matrícula no vulnera el derecho a la educación.

Asimismo, la AP de Pontevedra ratificó un auto dictado por el Juzgado de Primera Instancia de Vigo en el que estima la petición de un padre de vacunar a sus hijos menores, aunque la madre se oponía a ello aun siendo ésta quien ostentaba la custodia de los menores. Señala que "nos encontramos ante una materia en la que es criterio primordial el del "favor Filii" o interés superior del hijo, por lo que los Tribunales deben tratar de indagar cuál es el verdadero interés del menor, aquello que le resultará más beneficioso, no sólo a corto plazo, sino en el futuro. Así el artículo 2.1 de la Ley Orgánica 1/1996, de 15 de enero, de Protección Jurídica del Menor declara que «todo menor tiene derecho a que su interés superior sea valorado y considerado como primordial en todas las acciones y decisiones que le conciernan, tanto en el ámbito público como privado. En la aplicación de la presente ley y demás normas que le afecten, así como en las medidas concernientes a los menores que adopten las instituciones, públicas o privadas, los Tribunales, o los órganos legislativos primará el interés superior de los mismos sobre cualquier otro interés legítimo que pudiera concurrir»". Continua indicando que "ciertamente en España no existe la obligación de vacunar, sí hay un calendario de vacunación que puede variar de una comunidad autónoma a otra y que es una simple recomendación, por lo que la decisión final sobre si vacunar o no a los hijos corresponde a sus padres, pero en este caso se plantea la discrepancia sobre esta cuestión entre ambos 
progenitores -aun cuando inicialmente la misma pudiera no haber existido- lo que lleva al planteamiento del presente procedimiento judicial"12.

Asimismo, el Juzgado de Lugo $^{13}$ ha autorizado judicialmente para administrar la vacuna anti COVID-19 a un adulto que presenta discapacidad psíquica, a pesar de la oposición de la tutora -la hermana-, por considerar que la vacuna está indicada al pertenecer el incapacitado a un grupo vulnerable, siendo el balance riesgo/beneficio favorable a la vacunación. Estima que la renuncia de la tutora a la aplicación de la vacuna a su hermano resultaría contraria a los intereses del discapaz, considerando más beneficioso para la protección de su salud la dispensación de tal vacuna, pues el mismo se encuentra institucionalizado en un ámbito residencial, lo que implica mayores riesgos de contagio dada su situación de convivencia estrecha con otros residentes, así como por el acceso al centro de múltiples personas.

\section{Consentimiento informado}

El consentimiento informado surge en 1957 en el ámbito del Derecho Internacional, buscando una explicación jurídica a la obligación del médico o investigador de revelar información según la capacidad de comprensión de cada paciente, para que este pueda ejercer el derecho a autorizar o rechazar una intervención biomédica.

No obstante, su conceptuación desde el punto de vista ético se halla en el Corpus Hipocrático, a través del cual la ética en la medicina se incorporó al ejercicio de la moral, de tal forma que los médicos se comprometen a proteger a los pacientes de los daños que puedan causarles en el ejercicio de su actividad. De ahí, el secreto profesional médico, y la obligación de mantener informados a los pacientes.

Asimismo, es conocido su origen en el juez estadounidense Benjamín Cardozo en el Caso Salgo (1914), que introdujo unos criterios sobre el consentimiento informado, que ahora forman parte del elenco jurídico internacional. En su sentencia declaró que "todo ser humano de edad adulta y juicio sano tiene el derecho a determinar lo que se debe hacer con su propio cuerpo; por lo que un cirujano que lleva a cabo una intervención sin el consentimiento de su paciente comete una agresión, por la que se pueden reclamar legalmente daños". Además, añadió que las únicas excepciones al ejercicio del derecho al consentimiento informado, admitidas por la jurisprudencia son en caso de emergencia cuando el paciente esté inconsciente y cuando sea necesario operar antes de que el consentimiento pueda ser obtenido.

\footnotetext{
12 Auto AP Pontevedra, de 22 de julio de 2019, rec. núm. 321/2019.

${ }^{13}$ Auto JPI núm. 4 Lugo, de 11 de febrero de 2021, auto núm. 64/2021.
} 
Desde el punto de vista normativo, a nivel internacional destacan diversos instrumentos normativos sobre este derecho. Así, destaca la Declaración de Ginebra de 1948, la Carta internacional de los Derechos Humanos, el Código Internacional de Ética Médica de 1949, o la Declaración de Helsinki de 1964, en la que se incide en que "el bienestar de la persona que participa en la investigación debe tener siempre primacía sobre todos los otros intereses". Asimismo, la Declaración Universal sobre Bioética y Derechos Humanos de la UNESCO de 2005 hace hincapié en el respeto a la autonomía de las personas capaces de tomar decisiones, la protección de las que no son capaces de hacerlo y de las poblaciones vulnerables. Su artículo 6.1 señala que "toda intervención médica preventiva, diagnóstica y terapéutica sólo habrá de llevarse a cabo previo consentimiento libre e informado de la persona interesada, basado en la información adecuada. Cuando proceda, el consentimiento debería ser expreso y la persona interesada podrá revocarlo en todo momento y por cualquier motivo, sin que esto entrañe para ella desventaja o perjuicio alguno". Y el artículo 6.2 indica que "la investigación científica sólo se debería llevar a cabo previo consentimiento libre, expreso e informado de la persona interesada. La información debería ser adecuada, facilitarse de forma comprensible e incluir las modalidades para la revocación del consentimiento. La persona interesada podrá revocar su consentimiento en todo momento y por cualquier motivo, sin que esto entrañe para ella desventaja o perjuicio alguno. Las excepciones a este principio deberían hacerse únicamente de conformidad con las normas éticas y jurídicas aprobadas por los Estados, de forma compatible con los principios y disposiciones enunciados en la presente Declaración, en particular en el Artículo 27, y con el derecho internacional relativo a los derechos humanos".

Asimismo, el artículo 5 Convenio del Consejo de Europa, para la protección de los derechos humanos y la dignidad del ser humano con respecto a las aplicaciones de la biología y la medicina, y el artículo 3.2 Carta Europea de Derechos Humanos recogen el consentimiento informado, señalando expresamente que "en el marco de la medicina y la biología se respetarán en particular: el consentimiento libre e informado de la persona de que se trate, de acuerdo con las modalidades establecidas en la ley".

En nuestro ámbito interno, destaca la Ley 41/2002, Básica reguladora de la Autonomía del Paciente y Derechos y Obligaciones en materia de Información y Documentación Clínica, cuyo artículo 2.6 señala que "todo profesional que interviene en la actividad asistencial está obligado no sólo a la correcta prestación de sus técnicas, sino al cumplimiento de los deberes de información y de documentación clínica, y al respeto de las decisiones adoptadas libre y voluntariamente por el paciente".

Significa ello que se impone para los profesionales el deber de cumplir la lex artis, no sólo material, sino también formal. La lex artis material hace referencia a la correcta 
prestación de las técnicas médicas propias de cada especialidad, mientras que la formal al cumplimiento de los deberes de información y documentación clínicas y el respeto a la autonomía de la voluntad del paciente. De hecho, según el $\mathrm{TC}^{14}$ tanto la información como el consentimiento son dos derechos íntimamente relacionados, pues sólo si se dispone de la información suficiente y adecuada se podrá prestar libremente el consentimiento. Por tanto, como indica la doctrina, "el paciente por el hecho de serlo y acudir a la asistencia médica no pierde su dignidad de persona humana ni los derechos que le son inherentes, entre los que se encuentra la libertad y, más en concreto, el derecho de autodeterminación, con relación a su salud"15. Así tiene derecho a conocer todo lo relacionado con su enfermedad, esto es, diagnóstico, efectos, consecuencias, así como posibles tratamientos y sus efectos secundarios, para, a partir de todo ello, decidir libremente lo que crea y quiera como más conveniente.

Su artículo 3 define el consentimiento informado como "la conformidad libre, voluntaria y consciente de un paciente, manifestada en el pleno uso de sus facultades después de recibir la información adecuada, para que tenga lugar una actuación que afecta a su salud".

El artículo 4.2 Ley 41/2002 recoge la información como un elemento esencial, debiendo ser adecuada, verdadera y comprensible, y dejando constancia de la misma en la historia clínica. El artículo 8.2 Ley 41/2002 regula el consentimiento informado indicando que "será verbal por regla general. Sin embargo, se prestará por escrito en los casos siguientes: intervención quirúrgica, procedimientos diagnósticos y terapéuticos invasores y, en general, aplicación de procedimientos que suponen riesgos o inconvenientes de notoria y previsible repercusión negativa sobre la salud del paciente".

De esta forma, el consentimiento constituye la principal manifestación de la autonomía de la voluntad en la relación médico-paciente, siendo, generalmente verbal, salvo los supuestos tasados de la Ley 41/2002 en que será por escrito. La exigencia del consentimiento por escrito vendrá determinada, pues, si se considera que la vacunación es un procedimiento invasor que supone riesgos o inconvenientes de notoria y previsible repercusión negativa sobre la salud.

El incumplimiento del consentimiento informado puede constituir una vulneración del derecho fundamental a la integridad física ex artículo $15 \mathrm{CE}$, aunque la mera falta del consentimiento no supone violación de dicho derecho fundamental, pues deberá estarse a

\footnotetext{
${ }^{14}$ STC 37/2011, de 28 de marzo.

${ }^{15}$ JiMÉNEZ PARIS, José Miguel, "Vacunas Covid-19 y autorización judicial”, Diario la Ley, núm. 9808, 2021 (versión on line).
} 
las circunstancias del caso, ya que no se trata de un derecho absoluto e ilimitado, pudiendo ceder ante intereses constitucionalmente relevantes.

Según el Tribunal Supremo, en relación con el consentimiento informado sobre la inoculación a un varón sano de 37 años de la vacuna de la gripe, señala que "es bastante con que en el acto de la inoculación del virus se advierta verbalmente a la persona que lo recibe de aquellas consecuencias leves que pueden presentarse y que desaparecerán en breve tiempo y se indique los medios para paliar sus efectos" $" 16$.

Asimismo, señala el Tribunal Supremo, en relación con la vacuna contra la varicela, que "el consentimiento informado no alcanza a aquellos riesgos que no tienen un carácter típico, por no producirse con frecuencia ni ser específicos del tratamiento aplicado, siempre que tengan carácter excepcional, como es aquí el caso, en que la prueba practicada resulta que la cerebelitisposvacunal es rarísima"17. Para el Tribunal Supremo, el consentimiento informado constituye un "derecho humano fundamental (...) derecho a la libertad personal, a decidir por sí mismo en lo atinente a la propia persona y a la propia vida y consecuencia de la autodisposición sobre el propio cuerpo", conformándose como una manifestación "necesaria o explicación de los clásicos derecho a la vida, a la integridad física y a la libertad de conciencia"18.

Como se ha señalado, aunque, en principio, el consentimiento informado es básicamente verbal, sin embargo, éste debe ser por escrito en cirugías, procedimientos diagnósticos y terapéuticos invasores $\mathrm{y}$, en general, en procedimientos que supongan riesgos $\mathrm{o}$ inconvenientes de notoria y previsible repercusión negativa para la salud. Ello significa que, aunque, las reacciones adversas a las vacunas son excepcionales, pero pueden ser

\footnotetext{
${ }^{16}$ STS de 9 de octubre de 2012, rec. núm. 40/2012.

${ }^{17}$ STS de 12 de septiembre de 2012, rec. núm. 1467/2011.

${ }^{18}$ STS, sala de lo civil, de 30 de marzo de 2010, rec. núm. 326/2006, que señala que "la información del médico preceptiva para que el enfermo pueda escoger en libertad dentro de las opciones posibles que la ciencia médica le ofrece al respecto e incluso la de no someterse a ningún tratamiento, ni intervención, no supone un mero formalismo, sino que encuentra fundamento y apoyo en la misma Constitución Española, en la exaltación de la dignidad de la persona que se consagra en su artículo 10.1, pero sobre todo, en la libertad de que se ocupan el artículo 1.1 reconociendo la autonomía del individuo para elegir entre las diversas opciones vitales que se presenten de acuerdo con sus propios intereses y preferencias-sentencia del Tribunal Constitucional 132/1989, de 18 de junio- en el artículo 9.2, en el 10.1, y además en los Pactos Internacionales como la Declaración Universal de Derechos Humanos de 10 de diciembre de 1948, proclamada por la Asamblea General de las Naciones Unidas, principalmente en su preámbulo y artículos 12, 18 a 20, 25, 28 y 29, el Convenio para la Protección de los Derechos Humanos y Libertades Fundamentales, de Roma de 4 de noviembre de 1950, en sus artículos 3, 4, 5, 8 y 9, y del Pacto Internacional de Derechos Civiles y Políticos de Nueva York de 16 de diciembre de 1966, en sus artículos $1,3,5,8,9$ y 10 ".
} 
muy graves, convendría tener en cuenta que el consentimiento es un medio de prueba de la información, por lo que debería dejarse constancia del consentimiento por escrito.

Como es sabido, diversos órganos judiciales han obligado a vacunar contra el coronavirus a diversos ancianos y sujetos incapacitados. Así, ha sucedido en el caso de una anciana incapacitada, a pesar de la oposición de su hija, en cuyo caso el juzgado de guardia de Santiago de Compostela ${ }^{19}$ decidió que la mujer que vive en una Residencia para mayores sea inmunizada con la vacuna de Pfizer y BioNTech, tras el informe forense favorable, porque su salud debe prevalecer sobre la opinión contraria de su hija. Según el órgano judicial, "vacunarse y no hacerlo conllevan un riesgo que forzosamente ha de asumirse pues no caben opciones intermedias. En tal tesitura, la cuestión se reduce a una pura ponderación de cuál sea el riesgo mayor". "Y este riesgo se incrementa, también de manera indudable, a medida que la administración de la vacuna se demora y el número de contagios aumenta porque, en la misma progresión, es previsible que lo haga la posibilidad de contraer la enfermedad".

Asimismo, otro Juzgado de Primera Instancia ha autorizado al servicio médico-sanitario de una residencia a suministrar la vacuna contra el coronavirus a una mujer de 86 años "que no se encuentra capacitada para adoptar de una forma válida y consciente cualquier tipo de decisión que afecta a su salud" ${ }^{20}$, tras la negativa de su hijo a otorgar su consentimiento para la vacunación. El órgano judicial considera que "la solución que debe darse al presente proceso debe ser examinada de forma predominante desde la óptica de la protección de la salud" de la mujer "por cuanto que las posibles implicaciones relativas a la salud pública, que en este caso suscita, no pueden ser objeto de valoración exclusiva en el expediente de naturaleza civil, por más que su imbricación sea evidente, y ello dado el carácter voluntario de la citada vacunación". El Juzgado estima que, pese a la oposición del hijo de no otorgar su consentimiento a la vacunación, dichos argumentos "deben decaer frente al carácter seguro de la vacuna COVID-19, que cuenta con la aprobación de la Agencia Europea del medicamento, siendo en todo caso mayor y más grave el riesgo de contraer la infección por coronavirus que la de padecer algún efecto secundario grave". Sin embargo, el mismo órgano judicial, subraya que "no existe una obligación legal de vacunación". Por tanto, el mismo juez es consciente que la vacunación no es obligatoria en base a la normativa vigente.

\footnotetext{
${ }^{19}$ Auto de 9 de enero de 2021.

${ }^{20}$ Auto Juzgado Primera Instancia núm. 17 Sevilla, de 15 de enero de 2021, auto núm. 47/2021.
} 


\section{4. ¿Es posible establecer la obligatoriedad de la vacunación en el ámbito laboral?}

\subsection{Contexto normativo laboral general}

En el ámbito laboral, debe acudirse a la LPRL, la cual establece en su artículo 14 el deber de las empresas de garantizar una protección eficaz frente a los riesgos laborales a sus personas trabajadoras, debiendo garantizar la seguridad y salud en los aspectos relacionados con el trabajo. El artículo 14 LPRL establece el deber empresarial de otorgar una protección "eficaz" a la persona trabajadora para garantizar la seguridad y la salud en todos los aspectos relacionados con el trabajo y la obligación de adoptar todas las medidas que sean necesarias. Este deber se configura con un carácter amplio mediante la aplicación de las medidas y del desarrollo de las actividades que sean necesarias para evitar o disminuir los riesgos que puedan afectar a la salud y a la integridad de la persona trabajadora.

Esta deuda de seguridad de la empresa constituye, por otro lado, la manifestación de la protección constitucional de la vida e integridad física de la persona trabajadora, que vendría a insertarse en el contrato de trabajo opelegis, como deber contractual. La deuda de seguridad significa que quien se beneficia del trabajo prestado por otro en ajenidad y dependencia creando riesgos debe asumir la responsabilidad derivada de los mismos ${ }^{21}$. Este deber público no consiste sólo en una aplicación por la LPRL como consecuencia del artículo 43 CE y de sus normas de desarrollo, sino que se basa en un derecho subjetivo previo de la persona trabajadora derivado del artículo $15 \mathrm{CE}$ (derecho a la vida y a la integridad física) y, por tanto, ejercitable directamente frente a la empresa cuando se den riesgos frente a los citados valores constitucionales ${ }^{22}$.

No obstante, su artículo 29 recoge una serie de obligaciones de las personas trabajadoras, entre ellas, la de cooperar para que su empresa pueda garantizar unas condiciones de trabajo seguras y que no entrañen riesgos para la seguridad y la salud de la plantilla. Sin embargo, no se recoge en modo alguno la posibilidad de imponer la vacunación con carácter obligatorio.

De hecho, la vacunación aparece recogida únicamente en el artículo 8.3 RD 664/1997, sobre la protección de los trabajadores contra los riesgos relacionados con la exposición

\footnotetext{
${ }^{21}$ Sempere Navarro, Antonio Vicente, García Blasco, Juan, González Labrada, Manuel, Cardenal Carro, Miguel, Derecho de la seguridad y salud en el trabajo. Pamplona, Aranzadi, 1996. p 158, Montoya Melgar, Alfredo, Pizá Granados, Jaime, Curso de seguridad y salud en el trabajo. Madrid, Mc Graw Hill, 1996. p. 78.

${ }^{22}$ Blasco Lahoz, José Francisco, LóPez Gandía, Juan, Curso de Prevención de Riesgos Laborales. Valencia, Tirant lo Blanch, 2019.
} 
a agentes biológicos, que señala que "cuando exista riesgo por exposición a agentes biológicos para los que haya vacunas eficaces, éstas deberán ponerse a disposición de los trabajadores, informándoles de las ventajas e inconvenientes de la vacunación".

El problema es que este reglamento sólo se aplica a los colectivos específicos del sector biosanitario (médicos/as, enfermeros/as y técnicos de laboratorio), pero, además, de forma voluntaria.

Ello significa pues, que la empresa tiene la obligación de ofrecer el tratamiento, pero la persona trabajadora es quien decide al final si se somete o no. Por tanto, prevalece el derecho individual de cada persona a la intimidad corporal frente al colectivo y la protección de la salud de los demás.

Según la $\mathrm{AN}^{23}$, en relación a una reclamación contra el Ministerio de Sanidad por no haber previsto un régimen de vacunación obligatorio contra la poliomielitis, señala que "hay que indicar que este tipo de medidas se dirigen a personas sujetas a una relación especial (por ejemplo, militares o personal sanitario); si se trata de ciudadanos en general, puede exigirse para determinados viajes al extranjero o como condición para entrar en España". Fuera de estos casos, "sólo cabría justificar la vacunación obligatoria en una situación extraordinaria que excepcione el principio general de autonomía", tanto de los pacientes como de cualquier ciudadano a la hora de someterse a tratamientos preventivos, como en este caso sería la vacuna (artículo 10.9 Ley General de Sanidad y 9.2 de la Ley 41/2002, reguladora de la autonomía del paciente). Asimismo, señala que las libertades y derechos fundamentales reconocidos por la Constitución para cualquier ciudadano "no pueden ser privados por la celebración de un contrato de trabajo".

\subsection{Contexto normativo del personal sanitario}

En el caso del personal sanitario, cabe tener en cuenta que este colectivo constituye un grupo de riesgo, de tal forma que, en materia de vacunación, podría plantearse con carácter obligatorio.

Para ello, cabe tener en cuenta especialmente, el artículo 22 LPRL, que establece que " $\mathrm{el}$ empresario garantizará a los trabajadores a su servicio la vigilancia periódica de su estado de salud en función de los riesgos inherentes al trabajo. Esta vigilancia sólo podrá llevarse a cabo cuando el trabajador preste su consentimiento. De este carácter voluntario sólo se exceptuarán, previo informe de los representantes de los trabajadores, los supuestos en los que la realización de los reconocimientos sea imprescindible para

\footnotetext{
${ }^{23}$ SAN, sala de lo contencioso-administrativo, de 29 de septiembre de 2020.
} 
evaluar los efectos de las condiciones de trabajo sobre la salud de los trabajadores o para verificar si el estado de salud del trabajador puede constituir un peligro para el mismo, para los demás trabajadores o para otras personas relacionadas con la empresa o cuando así esté establecido en una disposición legal en relación con la protección de riesgos específicos y actividades de especial peligrosidad".

Por tanto, en este caso, los riesgos biológicos propios de la actividad sanitaria podrían llevar a entender que se trata de uno de los supuestos de excepción a la voluntariedad del reconocimiento médico para los profesionales sanitarios (el citado artículo 8.3 RD 664/1997).

No obstante, no debe olvidarse que, de forma expresa no se recoge en ninguna previsión normativa la obligatoriedad de la vacunación. Además, la Orden ESS/1451/2013, de 29 de julio, por la que se establecen disposiciones para la prevención de lesiones causadas por instrumentos cortantes y punzantes en el sector sanitario y hospitalario, dispone en su artículo 6 que si la evaluación de riesgos revela que existe un riesgo para la salud y la seguridad de las personas trabajadoras por exposición a agentes biológicos para los que existen vacunas eficaces, la vacunación debe serles ofrecida.

Por tanto, la vacunación debe ser ofrecida por la empresa, pero es de aceptación voluntaria por la persona trabajadora, sin que el rechazo de la misma les pueda suponer ningún efecto colateral en el trabajo.

\subsection{Despido de una persona trabajadora por negarse a ser vacunada, ¿es posible?}

En el supuesto de despido de una persona trabajadora por negarse a ser vacunada, como no tendría ninguna base legal, se trataría de un despido sin causa o acausal.

En estos casos, no existe una posición nada clara entre la doctrina judicial y jurisprudencial pudiendo encontrar líneas totalmente opuestas.

Por un lado, un sector judicial ${ }^{24}$ considera que los despidos sin una causa real justificadora de la decisión rescisoria del contrato son nulos. Consideran que los despidos acausales son nulos en base a dos preceptos del Código Civil. Por un lado, el artículo $6.3 \mathrm{CC}$, según el cual "los actos contrarios a las normas imperativas y a las prohibitivas son nulos de pleno derecho, salvo que en ellas se establezca un efecto distinto para el caso de contravención", y, por otro lado, el artículo $6.4 \mathrm{CC}$, según el cual "los actos realizados

\footnotetext{
${ }^{24}$ SJS núm. 6 Sabadell, de 6 de julio de 2020, st. núm. 93/2020; SJS núm. 6 Oviedo, de 22 de octubre de 2020, proc. núm. 305/2020; SJS núm. 29 Barcelona, de 28 de julio de 2020, st. núm. 180/2020, referidos a despidos de trabajadores en el marco de la crisis sanitaria provocada por el COVID-19 sin causa real.
} 
al amparo del texto de una norma que persigan un resultado prohibido por el ordenamiento jurídico, o contrario a él, se considerarán ejecutados en fraude de ley y no impedirán la debida aplicación de la norma que se hubiere tratado de eludir". En este sentido, el acto extintivo, al alejarse de los fines predeterminados para justificar la disolución lícita, deviene sin justificación, y, por consiguiente, ilícito. La actuación empresarial es contractualmente ilegal, tal y como así se deriva del Convenio núm. 158 OIT $^{25}$. Además, la nulidad es la calificación prevista tanto en el artículo 122.2 b) LRJS, en la modalidad procesal de impugnación de despido objetivo individual cuando se aprecia fraude de ley, y aunque podría objetarse que esta calificación se vincula al fraude de ley por elusión del procedimiento de despido colectivo, el Tribunal Supremo ${ }^{26}$ lo ha extendido a otros supuestos, considerando que "la decisión extintiva tomada por la empresa dentro del período de suspensión de los contratos de trabajo, sin causa suficiente, implica, a juicio de la Sala, el ejercicio de un derecho de forma contraria a la buena fe, quebrantando la confianza suscitada en los trabajadores afectados por los propios actos de la empresa, e incurriendo en un abuso de derecho, todo lo que ha de conducir, en aplicación de los artículos 53 del Estatuto de los Trabajadores y 122 de la Ley Reguladora de la Jurisdicción Social, en relación con el artículo 7.1 y 2 del Código Civil, como en casos análogos de fraude de ley, ha establecido la Sala -sentencias, entre otras de 20 y 17 de febrero de 2014 (rcud. 116/2013y142/2013)- a la declaración de nulidad del despido producido".

Otro sector judicial ${ }^{27}$ aboga por la declaración de improcedencia, pues se considera que "en nuestro régimen jurídico laboral la extinción del contrato de trabajo debe responder a una justa y tasada causa, no admitiéndose el simple desistimiento empresarial, salvo en algunas relaciones laborales especiales" 28 .

\footnotetext{
${ }^{25}$ En el mismo sentido aboga la STSJ Cataluña, de 6 de junio de 2019, rec. núm. 395/2019.

${ }^{26}$ STS de 12 de marzo de 2014, rec. núm. 673/2013.

${ }^{27}$ SSJS núm. 26 Barcelona, de 10 y 31 de julio de 2020, proc. núm. 348/2020 y 348/2020-B, respectivamente. Así también, SJS núm. 1 León, de 1 de octubre 2020, proc. núm. 253/2020. En términos similares, SJS núm. 5 Valladolid, de 21 de julio de 2020, proc. núm. 237/2020; SJS núm. 1 Mieres, de 4 de agosto de 2020, proc. núm. 319/2020; SSJS núm. 1 León (dos), de 22 de septiembre 2020, proc. núm. 261/2020 y 331/2020; SJS núm. 1 Palencia, de 1 de octubre de 2020, proc. núm. 281/2020; SJS núm. 1 Soria, de 9 de septiembre de 2020, proc. núm. 216/2020; SJS núm. 3 Gijón, de 3 de noviembre de 2020, proc. núm. 316/2020; SJS núm. 3 Ciudad Real, de 29 de septiembre de 2020, proc. núm. 234/2020; SJS núm. 26 Barcelona, de 13 de octubre de 2020, st. núm. 229/2020; SJS núm. 4 Valladolid, de 14 de octubre de 2020, proc. núm. 335/2020; SJS núm. 2 Salamanca, de 21 de octubre de 2020, proc. núm. 444/2020; SJS núm. 35 Barcelona, de 18 de noviembre de 2020, st. núm. 50/2020.

${ }^{28}$ SJS núm. 26 Barcelona, de 10 de julio de 2020, proc. núm. 348/2020.
} 
Se estima que la calificación de un despido sin causa, según la doctrina jurisprudencial ${ }^{29}$, incluso a los despidos no comunicados por escrito, verbales o tácitos, es la improcedencia y no la nulidad, ya que la nulidad queda reservada para los casos más graves, esto es, cuando se vulneran derechos fundamentales o relacionados con situaciones susceptibles de protección especial. Entiende que ni el régimen del fraude de ley o el del abuso de derecho de los artículos 6.4 y 7.2 CC, respectivamente, conllevan a la nulidad del despido, sino que ha de aplicarse la norma que se ha tratado de eludir - en el caso del fraude de ley-, y la correspondiente indemnización -para el abuso de derecho-. La nulidad sólo se contempla para los actos jurídicos contrarios a normas imperativas o prohibitivas, y sólo cuando en dichas normas no se haya previsto un efecto distinto.

Es decir, se considera que la nulidad está tasada, ya que "la nulidad del despido se impone pues de forma inequívoca y sin lugar a interpretación alguna cuando existe violación de derechos fundamentales, y en las materias conexas listadas de forma exclusiva, conforme a los artículos citados. En los casos en que no se cumplan los requisitos de forma, para evitar la indefensión del trabajador, el despido se calificará de forma automática y obligatoria como improcedente, con el abono de la máxima indemnización legal"30.

No obstante, se ha planteado que sería posible que, ante la falta de una norma que contemple esta especial circunstancia y obligue a la vacunación, se podría entender que concurre causa de despido disciplinario en aquellos casos en que las personas trabajadoras que se opongan a la administración de la vacuna contra el Sars-Cov-2, siempre y cuando la vacunación esté incluida dentro del Plan de Prevención de Riesgos Laborales de la empresa y pertenezcan a sectores en los que la vacunación proteja a las personas trabajadoras expuestas a dicho riesgo o estén en contacto con personas vulnerables. En cuanto a la normativa para poder justificar el despido disciplinario, se ha abogado por el artículo 29.3 LPRL que recoge que el incumplimiento por las personas trabajadoras de las obligaciones en materia de prevención de riesgos es considerado incumplimiento laboral a los efectos previstos en el artículo 58.1 ET. Asimismo, según el indicado artículo 8.3 RD 664/1997, “cuando exista riesgo por exposición a agentes biológicos para los que haya vacunas eficaces, éstas deberán ponerse a disposición de los trabajadores, informándoles de las ventajas e inconvenientes de la vacunación". Es decir, no se obliga a las personas trabajadoras a la vacunación, sino que se les informa sobre la posibilidad de hacerlo para que ellas decidan.

\footnotetext{
${ }^{29}$ Así lo zanjó la STS de 29 de septiembre de 2014, rec. núm. 3248/2013. En el mismo sentido STS de 5 de mayo de 2015, rec. núm. 2659/2014.

${ }^{30}$ STSJ Cataluña, de 21 de junio de 2020, rec. núm. 4708/2019.
} 


\section{Reflexiones finales}

No cabe duda de que, en la situación actual, la normativa española prioriza el derecho de la persona sobre su propio cuerpo frente al colectivo y la protección de la salud de los demás. Hasta el momento, el legislador no ha considerado necesario actualizar el marco legal planteando una solución a este posible conflicto.

No obstante, si acogiéndose a la LO 3/1986, y motivando una urgencia y situación de necesidad, las personas trabajadoras podrían verse obligadas a ser vacunadas sin que pudieran negarse, primando, entonces, el interés colectivo sobre el individual. Pero ello no es factible. Además, así lo indica claramente la Resolución 2361/2021 de la Asamblea Parlamentaria del Consejo de Europea que establece en su apartado 7.3.1 que "with respect to ensuring high vaccine uptake: 7.3.1. ensure that citizens are informed that the vaccination is NOT mandatory and that no one is politically, socially, or otherwise pressured to get themselves vaccinated, if they do not with to do so themselves" 31 .

Como se observa esta resolución manifiesta de forma expresa no solamente la voluntariedad en la vacunación, sino también que nadie puede ser presionado mediáticamente para que se vacune.

De igual forma, tampoco es lícito que una empresa pueda proceder al despido de una persona trabajadora por haberse negado a la administración de la vacuna, ya que, en ese caso, se estaría vulnerando su derecho fundamental a la integridad física y moral.

Ello no significa que, al igual que en el caso de la vigilancia de la salud, la empresa deba ofrecer la vacunación, siendo para la persona trabajadora totalmente libre su sometimiento o no, salvo en el caso en que exista un riesgo por agente biológico, en cuyo caso, sí podría devenir obligatorio.

De ahí que deba considerarse también que el despido de las personas trabajadoras por el hecho de negarse a que se les administre la vacuna debe ser declarado nulo. Estaríamos ante un despido fraudulento ex artículo 6.4 CC, y ex artículo 4 Convenio núm. 158 OIT, el cual se refiere a la necesidad de que el empresario tenga una justa causa para poder despedir, pues el citado precepto señala que "no se pondrá término a la relación de trabajo de un trabajador a menos que exista para ello una causa justificada relacionada con su capacidad o su conducta o basada en las necesidades de funcionamiento de la empresa, establecimiento o servicio".

\footnotetext{
${ }^{31}$ Disponible en https://pace.coe.int/en/files/29004
} 


\section{Bibliografía}

Blasco Lahoz, José Francisco, Gandía, Juan López, Curso de Prevención de Riesgos Laborales. Valencia, Tirant lo Blanch, 2019.

Cierco SeIRA, César, "Vacunación obligatoria o recomendada: acotaciones desde el Derecho", Elsevier, 21 (1), 2020.

Comité Asesor de Vacunas de la Asociación Española de Pediatría, Manual de Vacunas en línea de la AEP, 2014. Disponible en https://vacunasaep.org/documentos/manual/manual-de-vacunas.

Comité de Bioética de España, Cuestiones ético-legales de rechazo a las vacunas y propuestas para debate necesario. Disponible en http://assets.comitedebioetica.es/files/documentacion/cuestiones-etico-legales-rechazovacunas-propuestas-debate-necesario.pdf

JIMÉNEZ PARIS, José Miguel, "Vacunas Covid-19 y autorización judicial", Diario la Ley, núm. 9808, 2021 (versión on line)

Montoya Melgar, Alfredo, PizÁ Granados, Jaime, Curso de seguridad y salud en el trabajo. Madrid, Mc Graw Hill, 1996.

Sempere Navarro, Antonio Vicente, García Blasco, Juan, González labrada, Manuel, Cardenal Carro, Miguel, Derecho de la seguridad y salud en el trabajo. Pamplona, Aranzadi, 1996.

TOlosa TRIBIÑo, César, "Problemas legales de la vacunación en España", Diario La Ley, 22 de enero de 2021. 